\title{
Does Corruption Have Social Roots? The Role of Culture and Social Capital
}

\author{
José Atilano Pena López \\ José Manuel Sánchez Santos
}

\section{Abstract}

The aim of this work is to analyse the influence of sociocultural factors on corruption levels. Taking as starting point Husted (J Int Bus Studies 30:339-359, 1999) and Graeff (In: Lambsdorff J, Taube M, Schramm M (eds) The new institutional economics of corruption. Routledge, London, 2005) proposals, we consider both the interrelation between cultural dimensions and the diverse expressions of social capital with corruption. According to our results, the universalistic trust (linking and bridging social capital) constitutes a positive social capital that is negatively linked to corruption. In contrast, the particularistic levels of trust (bonding) can constitute a negative social capital directly related to corruption levels. Furthermore, cultures which are favourable to the legitimation of dependency relations and the formation of closed particularistic groups (power-distance and community factors) create a breeding ground for the development of these amoral rent-seeking structures.

Keywords

Social capital Corruption Cultural factors New Economic Sociology

\section{Introduction}

The study of corruption requires a multidisciplinary approach as it cannot be isolated from the social environments in which it arises. The approximation undertaken by the Economic Analysis has sought to integrate an institutionalist perspective with mixed results. ${ }^{1}$ In this area the most tackled issue and with the greatest convergence of results are the effects of corruption. The vast majority of these studies agree in establishing an inverse relationship between corruption, economic growth (Mauro 1995; Lambsdorff 1998; Hall and Jones 1999; Jain 2001), and human development (Akçay 2006). ${ }^{2}$ On the contrary, the analysis of the causality of corruption remains a controversial topic in the field of studies on the social determinants of economic activity.

The lines of research proposed from a neo-institutionalism stance have focused the analysis on the interaction between individuals and institutions (formal and informal rules governing life in society). According to this approach, the origin of the problem lies in institutional and organizational aspects. The agents will succumb to corrupt practices if they have discretion, weak accountability, and a substantial monopoly of power at their disposal. Consequently, reformers could reduce corruption by curtailing this discretion, increasing control over officials and reducing the power of the state. 
However, these policy proposals have barely proved effective in the long run (Riley 1998; Rose-Ackerman 2000). ${ }^{3}$

This microeconomic approach based on principal-agent has its shortcomings insomuch as it ignores the interrelationship between structure and agency, omitting the socioeconomic contexts in which transactions take place (Shihata, 2000). Evidence shows that individuals develop bureaucracies, corrupt practices, and attitudes conditioned by a broader socioeconomic environment. It is specifically culture, shared values and social networks in which individuals are inserted that influence behavior, the functioning of the economy and the institutional and legal basis (Hofstede 2003). Moreover, these factors which uphold the framework of society and, by extension, of the economy, and are hard to alter by means of policy actions (Treisman 2000; Paldam 2002).

In the same vein, business ethics should take into account the influence of cultural frameworks within the decision making context. The sociocultural context not only affects the perception of a situation or a rule, but it also affects the evaluation of the alternative behaviours and their consequences. (Hunt and Vitell 1986). Thus, an acultural evaluative approach to economic ethics, regardless of the deontological or consequentialist perspective, is futile. Consequently, it is necessary to understand how culture influences ethics and, in particular, how it affects the decision making process (Sen 1997).

In addition, delving a little more deeply into the causes of corruption requires complementing the institutional approach with a theory that accounts for the broader context, introducing sociocultural variables. To this end, we adopt the New Economic Sociology (NES) perspective which provides a general sociocultural theory explaining the foundations of corruption. ${ }^{4}$ Under this integrated social and economic perspective, exchanges are facilitated, and thus, so as to address behaviours deemed corrupt, it would be necessary to reconstruct the social and cultural system that underpins these conducts (Husted 1999, Rose-Ackerman 1999; Lambsdorff et al. 2005; Lambsdorff 2002).

From the NES perspective, the level of corruption in a society is associated with certain forms of trust and norms that materialize in social networks (social capital) and that project an evaluative configuration "a priori" about what is socially desirable (culture). In this sense, one would expect the prevalence of cultural models that emphasize social distance or a culture of dependency, coupled with low levels of generalized trust to play an important role in explaining corruption problems. Indeed, some values and norms stemming from them can favour a positive framework for the expansion of corrupt behaviour. This logic suggests that this problem will arise where trust is linked to networks and particularistic norms than to society as a whole. This paper analyzes the interrelationship between the various cultural models, expressed through the main differentiating factors, and social expressions, listed in social capital endowments, with observed levels of corruption. We build an explanatory model of the development of corruption that integrates those models based on social capital (Lambsdorff et al. 2005; Pena López and Sánchez Santos 2009) and those that incorporate cultural 
variables (Husted, 1999; Seleim and Bontis 2009). This which allows us to address the interrelationships both of values and the social structure with corruption.

The interest of this investigation is twofold: theoretical and practical. From the theoretical point of view, it is important to determine the contextual factors that foster this kind of behaviours and that weaken the conventional attempts to eradicate this problem. From the practical point of view, it is crucial to propose effective policies to isolate the dimensions of the culture that favour corruption.

The rest of the paper is structured as follows. The "The Sociocultural Context of Corruption" section focuses on the characterization of the problem of corruption and its sociocultural explanation: the cultural dimensions and social capital endowments in its various expressions. In the "Empirical Evidence"section we contrast empirically the hypothesis proposed for the structural determinants of corruption and in the "Conclusions" section, the main conclusions are drawn.

\section{The Sociocultural Context of Corruption}

A first approach to the structural roots of corruption involves defining the problem conceptually. As a starting point, we have Goode's definition (1984). From a legal point of view, an individual commits corruption when he is or is about to become a public official and accepts or obtains, either for himself or for another person, some form of irregular compensation different to that stipulated by law as a motive or reward for any official act, which favours or disfavours any individual or group of individuals. Although from the legal point of view the above characterization is widely accepted, Freisitzer (1981), from a sociological point of view, it provides us with a narrower definition for the purposes of this paper. According to this author, corruption is an action that deviates from the general normative expectations, in search for a personal benefit or for the benefit of a restricted group, mainly by misappropriation of a public resource.

This latter definition is particularly clear in pointing out that corruption is closely linked with the characteristics of the society referred to. Following the classical sociological terminology of Tönnies (1947 [1887]) we can contrast two extreme models: a cold society and a warm society. In the first type there are no relations between individuals and therefore interpersonal knowledge is very limited, even within families. In contrast, a warm society implies the existence of an extensive network of personal relationships and mutual knowledge. In these societies, family contacts are extremely frequent and the family is a strong network of mutual aid.

Both extreme social models have clear implications for the functioning of the government and public resources administration in general. Purely economical relations are more likely to be found within the context of a cold society, while social distance could be even considered as unacceptable in a warm one; that is, treating in the same manner those nearest to one would be considered inappropriate. In the latter, it is very difficult to distinguish between an act that can be branded as corrupt and any other social behaviour, because there may be no direct payment for the 
services but it can be pending over time and takes on the most varied social compensations.

In additionally, in warm societies with strong bonds inside the groups, the expectation that the official shall be impartial to the application of the norm is nonexistent. In this situation, to achieve a Weberian technical bureaucracy is unfeasible (Weber 1964), because the norms of respect in small circles are safer forms of conduct than those based on universal principles. Moreover, in extreme cases, these irregular behaviours among officials and individuals could end up being legitimate as a result of the entrenchment of these cultural principles. In such societies, the cost of the corrective role of government in the economy and in the field of economic relations with the private sector, is very high, hampering growth (Tanzi 1994).

Given this social conditioning, the traditional analysis of the economics of crime (Becker 1968; Becker and Landes 1974) would apply more so to cold societies. Then, the prosecution of a crime would only be effective in a modern state in the Weberian sense. On the contrary, the effectiveness of these methods in societies where particularistic relation networks survive, is severely limited because of the impossibility of determining payments and justifying and imposing penalties.

For neoinstitutionalist authors (Rose-Akerman 2000) corruption, in its elemental expression, is an agency problem that can be modelled through a scheme with three actors whose nucleus is a principal-agent relation and a third party (customer). The principal (authority, employer, state...) delegates the decision-making power and resources to the agent and the agent defrauds the principal rules by giving an illegal gain to the customer. Consequently, corruption involves the breach of a contractual relationship, both formal and informal, in which the agent receives a payment as a result of the abuse of their power of decision.

These kinds of relationships are socially conditioned. Corruption is an illegal behaviour that involves an asymmetric risk. Obviously, agent and customer cannot make any claim for this breach. Thus, the problem is to ensure the fulfilment of promises, even with the risk of being penalized when discovered. This presents two features: reciprocity (both actors' utilities must be interdependent) and secrecy (as corruption generates negative externalities). Thus, those values that favour dependency and integration in small communities or, what is the same, from the social point of view, those situations in which there are strong particularistic trust networks contribute to the generalization of these forms of informal patronage.

In the same vein, the expectation of repeated interactions in a social network and the ability to establish a relationship of dependency with the client, may create the opportunity to either reward or punish the other's behaviour. This generates forms of loyalty that reinforce the informal agreements (mafia...) (Husted 1994).

In short, to explain the extent of corruption in a given economy it is necessary to consider the legal system, the dimension of the state and the instruments managed by the authorities to achieve their objectives. However, the persistence of the problem in the long run seems associated with sociocultural factors. A particular configuration of 
the cultural dimensions and social networks will limit the impartiality of public actions and the ability to punish corruption. The following sections will review both dimensions: culture and social networks.

\section{The Dimensions of Culture and Corruption}

Culture is a comprehensive system of meanings, symbols, values, and assumptions about what is good or bad, legitimate or illegitimate which underlies the practices and norms in a society (Kluckhohn 1951, Hofstede 1999). In a very similar way, Geertz (1957) noted that culture is a web of meanings in terms of which human beings interpret their existence and experience, and drive their actions, that is, cultures are models of human behaviour and symbolic structures that give meaning to their conducts.

Culture influences and pervades every aspect of life and, although it is not deterministic, it is a subliminal system of thought that reflects the organization of values, norms and symbols of a particular society and influences the interactions and choices of individuals (Parsons and Shils 1990). The social structure, however, is the social form that action takes, the existing network of relationships. Consequently, culture and the social structure (society) are two closely related phenomena abstractions.

To classify cultural stereotypes is complex, especially as regards the definition of the identifying dimensions. In general we can consider the existence of two models: the four dimensions model of Hofstede (1999) and the seven dimensions model of Schwartz (1994).

In this paper we have chosen to use the Hofstede model, given its cultural amplitude and parsimony. ${ }^{5}$ This interpretive scheme, based on research undertaken with more than 120,000 surveys in 40 countries, integrates the differential features of cultures in four dimensions that have been stable over time: power-distance, individualismcollectivism, masculinity-femininity and risk aversion. A review of the nature of these proposed dimensions allows us to establish some basic assumptions about their impact on corruption levels.

The power-distance dimension is defined by Hofstede as the level of acceptance of unequal distribution of power by those members of the institutions that are in the lower ranks or, from another perspective, the need to maintain a social distance between superiors and subordinates.

The interpretation of the effects of this dimension is ambivalent. Thus, from the business ethics perspective, it is argued that in a society where the power-distance dimension is particularly evident, subordinates tend to adopt more formal decision criteria and directly depend on superiors in their ethics (Vitell et al. 1993).

However, if we adopt a socioeconomics point of view, high scores in this factor show a considerable culture of dependency of subordinates on their principals in the form of paternalism. Distances are accentuated and with them, the social networks patronage 
dependency. Principals favour agents or subordinates in return for their loyalty and the latter will obey their principals unequivocally. Thus, the decisions do not correspond to meritocratic criteria and can even create parallel agency relationships with a lack of transparency and weak accountability. Meanwhile, the distance can foster conditions in which the principals obtain an extra advantage because of their position (Husted 1999). This leads us to propose a first testable hypothesis.

\section{Hypothesis 1}

The culture of dependency and the lack of meritocratic principles characteristic of societies in which relationships are marked by power-distance dimension will tend to generate high levels of corruption.

The individualism-collectivism factor refers to the dominance of the individual identity against all forms of collectivism, that is, it reflects the extent to which individuals are integrated into cohesive groups and follow their guidelines. This variable highlights the extent to which the decisions depend on the individual or are determined by intragroup relations. In a more individualistic culture, people act in their interest, whereas in collectivist societies the individuals give priorities to collective interests, and expect loyalty and reciprocity from the group. There is a clear tendency to link this with the previous dimension, since those countries with little power-distance relationships are characterized by more individualism and transparency. In contrast, to integrate the group interests in individual decision making involves facilitating the development of corruption networks in which an individual gives preference to members of their group.

The proposed interpretation from ethics operates, however, the other way round. Those cultures where individualism prevails, the decision is made regardless of formal and informal aspects of the environment and without even preserving the interests of stockholders and stakeholders (Vitell et al. 1993). However, considering our starting position, the emergence of networks of corruption is more logical in societies where group preservation prevails over individual reasoning. Accordingly, our proposal will be:

\section{Hypothesis 2}

Those cultures marked by collectivism versus individualism will be more favourable to forms of corruption for their ability to build networks which defend the interests of closed groups.

Masculinity-femininity expresses the individual pursuit of material success or the existence of competitive attitudes versus the desire for quality of life. This dimension also reflects the persistence of distinctions in gender roles regarding concern to achieve a certain interpersonal harmony and equality. More feminine societies, as the Nordic ones, care especially about the quality of life and equality in gender roles. In this sense, the work already cited Vitell et al. (1993) noted that those cultures characterized by masculinity have less sensitivity on moral issues and are generally more tolerant in questionable practices. In these masculine societies the decision 
makers may simply fail to perceive certain moral issues considering them outside the realm of ethics. Thus, we can deduce a positive relationship between masculinity and the presence of corrupt relationships.

\section{Hypothesis 3}

The decision-makers in masculine cultures tend to be less sensitive to the perception of ethical problems and are not influenced by general formal or informal moral codes. Then, these societies tend to be more permissive with corruption.

Finally, riskaversion reflects the dislike towards novelty or change?, and the importance that is given to the stability and planning. Again, as in the first two dimensions, here the reasoning presented by the ethics diverges. For example, to Ouchi (1981) risk averse societies become more intolerant of deviant behaviours. On the contrary, favourable risk environments tend to adopt more risky decisions in which personal interests prevail over others. However, this interpretation is ambiguous. In a country where this feature is especially salient, individuals give a clear priority to the search for security and reject divergent behaviours. From our perspective, risk aversion is a major obstacle in entrepreneurship and the free market. Then, considering both risk aversion and group relations, the effect that would prevail is that of reinforcing corruption, since the latter is a common mechanism to reduce uncertainty within the group.

\section{Hypothesis 4}

The tendency to group protection coupled with risk aversion may promote the development of networks of corruption. Consequently, those societies with higher risk aversion tend to have higher levels of corruption.

In sum, our hypothesis states that those collectivist cultures with strong social inequalities (power-distance) or a certain culture of dependency, combined with a high interest in material achievements (masculinity) and risk aversion, will present higher levels of corruption than individualistic cultures with a low differentiation in terms of power-distance which focus on achievements in terms of quality of life and little risk averse.

\section{Corruption and Social Capital}

Economics distinguishes four categories of capital that describe the various types of resources that a community has access to. Two of them are relatively conventional: natural capital (natural environment) and physical capital. However, neither of them reflects the uniqueness of human beings, their capacities and relationships. For this reason, the concept of human capital (skills and knowledge) and social capital (relational structures), have completed the analysis of capital endowments of a particular community.

Among the many definitions that try to account for the concept of social capital we can highlight Coleman's (1988), Putnam's (1993) and Bourdieu's critical reinterpretation 
(1986). Synthesising these definitions we can conclude that social capital is made up of networks and social norms. The former refers to social networks in which individuals are inserted; these can be communication networks, or social and economic support. Meanwhile, social norms refer to social rules of reciprocity or mutual expectations of cooperation, ultimately, trust and common projects.

This characterization would encompass three forms of social capital under the same concept: (i) a bonding capital made up of family ties or relations with fellow members of the same family or a group of strong ties, (ii) a bridging capital or relationships with members of other (ethnical, socio-economical...) groups through weak ties (iii) an institutional bond capital (linking) or relationship between individuals and/or groups of individuals with any form of authority (Woolcock 2001). Thus, we can distinguish at least three framework levels: Relational microanalytical (or links between peers), mesoanalytical (or links between members of different groups) and macroanalytical (or social institutions).

While social networks and trust are constitutive expressions of social capital in the context of this analysis we take into consideration the relationship between corruption and capital. This is not obvious and is far from being a closed issue (Uslaner 2005; Paldam and Svendsen 2002; Grootaert 1998; Bjornskov, 2004). The complexity and ambiguity of the social capital concept, especially the existence of different expressions, requires examining the possible causal links between these and corruption, since the various types of social capital outlined above generate contradictory social effects.

Some specifications are required so as to explain the role of social capital in networks of corruption. The development of values and norms conducive to corruption will depend on the trust inside small groups and their closeness. That is, it is necessary to establish reasonable expectations of behaviour that would reinforce the informal contracts behind corruption. Secondly, contrary to what happens with positive social capital, negative social capital does not diminish when dependency diminishes, instead it stabilises. This is due to the limited dimension of the corruption networks and their closeness. $^{6}$

Generalist social capital expressions (linking and bridging) that refer to society as a whole (proxied by generalized trust and strong asociativeness) favour the functioning of the economy and society. However, expressions focused on particularistic networks with strong ties and the trust in these kinds of groups that we classified previously as bonding social capital relationships, can foster corruption (Graeff 2005). Consequently, societies with family trust and direct dependency networks, characterized by close and frequent exchanges, are more likely to develop networks that facilitate tacit contractual extension of corruption and even social acceptability. This is especially relevant when we find simultaneously high particularistic trust and a very low general trust (Pena López and Sánchez Santos 2009).

Universalist trust (linking and bridging) can be considered as a positive social capital, while micro level of social capital or bonding may be negative to the extent that they 
facilitate the establishment of mutual trust relationships contrary to social trust and develop tacit contracts based on these relationships.

According to these considerations:

\section{Hypothesis 5}

The endowment of positive social capital (the extension of open social networks, general trust and universalistic norms) is linked to low levels of corruption.

\section{Hypothesis 6}

Social capital based on particularistic norms and trust favours the erosion of agency relations and the development of corruption. In this case, social capital supports illegal exchanges, hence its classification as negative social capital.

In short, social capital influences the functioning of society positively if linked to universalistic ethical attitudes; attitudes and rules that require subjects to evaluate their own behaviour taking into account gains and losses perceived by not participating in their agreements (externalities). In contrast, micro and meso expressions can be associated with networks of corruption and even kleptocracies.

\section{Empirical Evidence}

Our empirical model analyzes the relationships between socio-cultural factors and structural indices of perceived corruption at a national level. According to the analytical framework adopted for the identification of sociocultural determinants of corruption, there should be an inverse relationship between corruption and general trust and a positive relationship with particularistic expressions. Moreover, we can expect a direct relationship between those proxies that underline the strength of interest groups, in the sense that Olson (1965) attributed to the term, and the presence of corruption. At the same time, the relationship between corruption and the dimensions of power-distance, communitarianism, masculinity, and risk aversion should be positive.

Although in our analysis the central variables are trust (social capital proxy) and cultural dimensions, we also include in the model indicators of openness, property rights and economic freedoms and human development, whose influence has already been highlighted in previous works on the subject mentioned above.

Data

The data in the econometric model come from several sources. First, the $\mathrm{K}$ Transparency International Index (2001) is used as a proxy of the level of corruption. This is a pool type index, which is constructed from multiple sources and scales perceived corruption from 0 to 10 . The highest score corresponds to situations where there is no corruption; it therefore is inversely associated with index values. The levels 
of development of each of the nations analyzed are studied from the factors that enter into the calculation of the HDI in the WDI (WorldDevelopment Indicators). Statistical information about economic and social values is derived from the World Values Survey wave in 2001. From this survey, (national) general and particular trust indicators are drawn as proxies of positive and negative social capital. ${ }^{7}$ The regulatory activism and interventionism versus free market (property protection, free movement of capital, etc.) is proxied with indices of civil liberties Freedom House International (2001). Finally, we use the cultural factor scores proposed by Hofstede (1999).

\section{Econometric Model}

The study of the correlations between the main variables considered in the econometric analysis indicate, on the one hand, the importance of the interplay between cultural and institutional variables and, secondly, the generalized trust and corruption (Table 1). 
Table 1Correlations * Significance $0.05,{ }^{* *}$ Significance 0.01

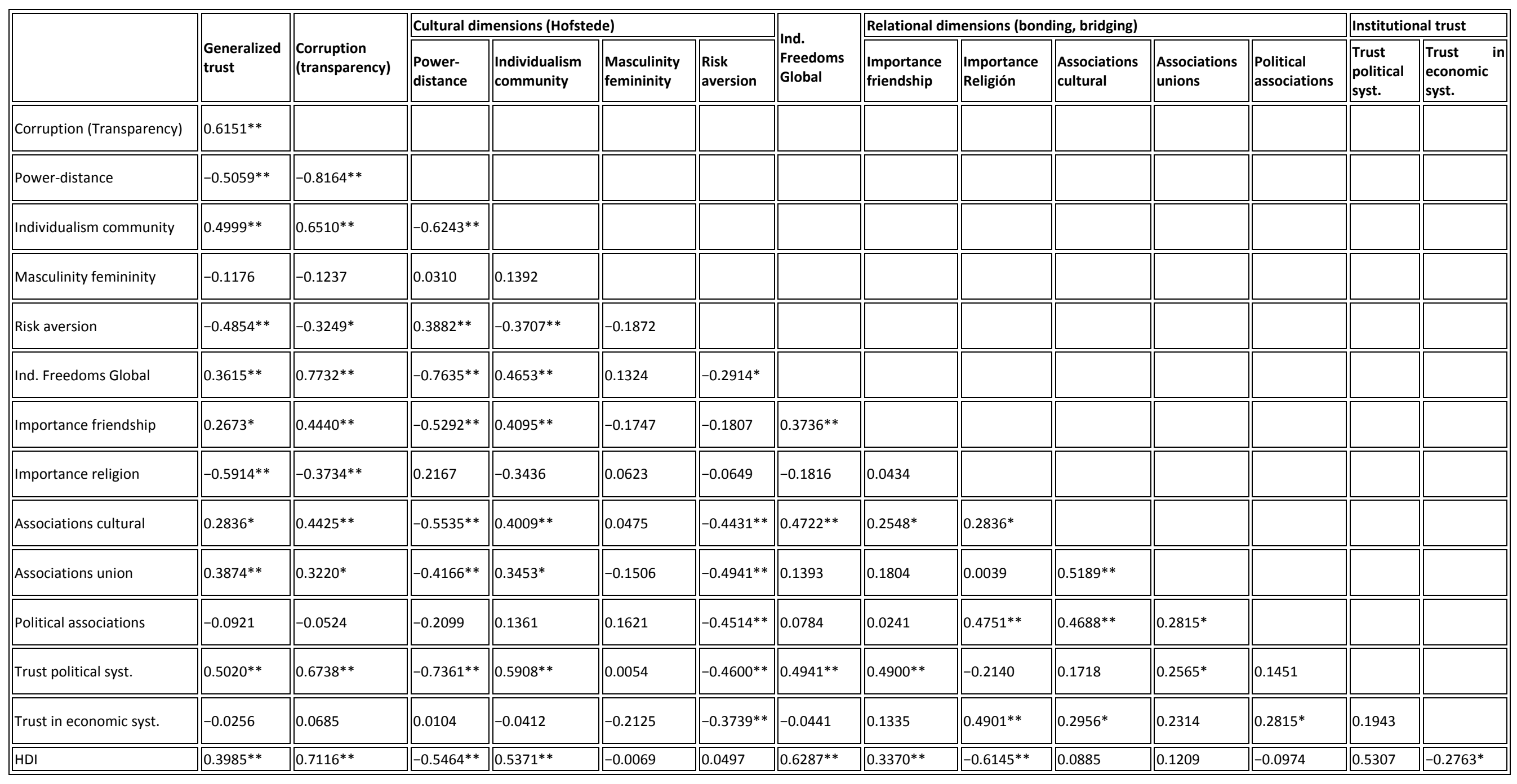


In the first place, there is a clear relationship between the dimensions of powerdistance, individualism and risk aversion. ${ }^{8}$ Those countries with more egalitarian relationships are prone to individualistic expressions and are more inclined to take risks. Meanwhile, regarding the relationship of these factors with micro and meso expressions of social capital it should be noted that those cases manifesting individualistic-egalitarianism and low risk aversion correspond with situations of high levels of horizontal association, ${ }^{9}$ general and institutional trust. This group of countries is compound basically made up of advanced economies with high levels of human development. In turn, this sociocultural framework can also be reflected within the institutional frameworks insomuch as this set of countries has smaller regulatory frameworks, that is, they are more liberal in economic terms.

The correlations between generalized trust and corruption suggest the existence of a link between the two variables and show that high levels of corruption (low levels of transparency) are associated with low levels of general trust. Similarly, the data for the factors of power-distance, individualism and risk aversion show a clear influence on the mentioned variables in the sense suggested by our hypothesis. Associationism operates in the same direction, although the extension of horizontal associations seems to boost trust and transparency, but not in the case of vertical expressions, as with the political and religious associations. The latter could be identified with olsonian interest groups and often have deleterious effects on the general trust and transparency.

The econometric analysis will allow us to determine the explanatory power of institutional, cultural and social variables on the corruption levels observed. ${ }^{10}$

The first set of regression models (Table 2, model I) examines the relationship between corruption and political variables, particularly those relating to state size, interventionism in economic activity and the legal definition of the economic activity framework. 
Table 2

Corruption versus institutional variables and social capital proxies

\begin{tabular}{|c|c|c|c|c|c|}
\hline \multicolumn{6}{|c|}{ Dependent variable: corruption (transparency), sample size: 60} \\
\hline $\begin{array}{l}\text { Explanatory } \\
\text { variable }\end{array}$ & Model I & Model II & Model III & Mod IV & Model V \\
\hline Generalized trust & & $0.104921^{* *}$ & & $0.059535 * *$ & $0.051697 * *$ \\
\hline Political trust & & & $\mid 0.086453^{* *}$ & $0.072832 * *$ & | $0.049382 * *$ \\
\hline \begin{tabular}{|l|} 
Importance of \\
family
\end{tabular} & & & $-0.091333 * *$ & $-0.066130 * *||$ & $\mid-0.046512^{* *}$ \\
\hline Trust in unions & & & & $-0.030226 *$ & $-0.016874 *$ \\
\hline $\begin{array}{l}\text { Trust in political } \\
\text { parties }\end{array}$ & & & & $-0.036143 * *$ & $-0.014683 * *$ \\
\hline $\begin{array}{l}\text { Trust in companies } \\
\text { (market) }\end{array}$ & & & & $0.033283^{*}$ & $0.027114^{*}$ \\
\hline $\begin{array}{|ll|}\text { Global } & \text { Freedom } \\
\text { Index } & \\
\end{array}$ & $1.168152 * *$ & & & & $0.645581^{* *}$ \\
\hline C & -2.965819 & 1.711817 & 8.196602 & 6.142601 & 0.615729 \\
\hline$R^{2}$ & 0.597809 & 0.378304 & 0.526499 & 0.701019 & 0.848384 \\
\hline Adjusted $R^{2-}$ & 0.590074 & 0.367585 & 0.509588 & 0.665844 & 0.824264 \\
\hline Prob $(F)$ & 0.000000 & 0.000000 & 0.000000 & 0.000000 & 0.000000 \\
\hline
\end{tabular}

* Significance $0.05, * *$ Significance 0.01

Although the results confirm theory statements about state intervention and the persistence of corruption problems, we should make some remarks. We found a significative relationship between corruption and the Global Economic Freedom Index; particularly with the definition of property rights, ${ }^{11}$ but the volume of public expenditure (public expenditure/GDP) is not significant. This suggests that the influence is not the size of the state but its regulatory activism. From the political point of view this result indicates that the lack of definition of property rights is the main variable explaining the existence of high levels of corruption. Moreover, this is consistent with Kranton (1996) and Tanzi's (1998) proposals on the conflict between market and patrimonialist systems of the public power exercise. Notwithstanding, this regression can be considered tautological because of the construction of this kind of indices.

On the contrary, the following models are focused on sociocultural variables. The analysis of the effects of social capital endowments corroborates some of the results of Uslaner's work (2002). Specifically, the estimation model II (see Table 2) shows a clear link between general social capital, defined with the proxy "generalized trust", 
and transparency or lack of corruption. Consequently, the regression analysis provides evidence that the lack of (not in sp. Translation) social capital endowment is a key cause of corruption.

However, this relationship must be analyzed in accordance with the considerations previously made about the confrontation between general and particularistic trust. Firstly, general trust is related to trust in the political system (in no particular party) and with the absence of corruption (transparency). Furthermore, the importance of strong family ties operates in the opposite direction (model III-Table 2). Thus, in a broader model in which different expressions of trust are considered, those expressions of trust in small groups (particularistic) are related with the presence of corruption problems (model IV-Table 2).

This can be interpreted as evidence of the importance of family ties or strong ties in groups of interest (political parties, trade unions, etc.) which favour corruption. Relationships of reciprocity established out of the market offer an alternative (second best) solution for those societies where there is poor performance because of institutional problems (Kaufmann and Kraay 2002).

According to this approach, the generalizations of market mechanisms would be a way of reducing corruption. In this respect, the role of the variable "trust in business" can be emphasized. Trust in the market and its performance seems to be associated with general trust and not with their particularistic expressions. This finding would be in line with Kranton's thesis (1996) on the confrontation of systems (Griesshaber and Geys 2011).

Model V (Table 2) combines the institutional and socio-cultural dimensions with a high explanatory capacity and support the hypothesis of this present study. On the one hand, it confirms the relationship between the different expressions of trust (particularist and generalist) and the levels of corruption. Furthermore, it appears that lack of transparency is closely linked with the greatest restriction of political and economic freedoms.

In sum, the distribution of countries in the sample highlights the influence of sociocultural, historical, and institutional factors as determinants of corruption. Cultural traditions seem to have a clear impact on general trust, so much so that some clusters of proximity could be established. Latin countries of Catholic tradition have generally low levels of confidence attached to a high presence of particularistic forms of trust or amoral familism (importance of family and peer groups). In contrast, Eastern societies tend to have relatively high levels of trust Former communist countries, however, have low levels of general trust linked to high levels of corruption. Finally, those countries of Protestant tradition are clearly situated at the highest levels of trust and transparency.

Table 3 shows the regression models explaining the observed levels of corruption considering the cultural dimensions. Power-distance and individualism-communitarianism variables 
exhibit a strong explanatory power and significance on the levels of corruption (Table 3-model VI). ${ }^{12}$

Table 3

Sociocultural variables versus corruption

\begin{tabular}{|c|c|c|c|c|c|}
\hline \multicolumn{6}{|c|}{ Dependent variable: corruption (transparency), sample size: 60} \\
\hline & Model VI & Model VII & Model VIII & Model IX & Model X \\
\hline Power-distance & $-0.07445 * *$ & & & & \\
\hline Log (power-distance) & & $-5.38738 * *$ & $-4.48780 * *$ & $-0.06436 * *$ & $\mid-2.01716 * *$ \\
\hline Individualism-collectivism & $0.02718 *$ & & & & \\
\hline General trust & & & $0.042611 * *$ & $0.066164 * *$ & $0.061642 * *$ \\
\hline Trust in parties & & & & $-0.024828 *$ & $\mid-0.02691^{*}$ \\
\hline Trust companies (market) & & & & & $0.029044^{*}$ \\
\hline Global freedom Ind. & & & & & $0.574197 * *$ \\
\hline C & $8.3397 * *$ & $26.86941 * *$ & $21.99991 * *$ & $7.718476 * *$ & $6.844724^{*}$ \\
\hline$R^{2}$ & 0.69922 & 0.716502 & 0.757445 & 0.774019 & 0.852509 \\
\hline Adjusted $R^{2}$ & 0.68614 & 0.710470 & 0.746900 & 0.758611 & 0.834950 \\
\hline $\operatorname{Prob}(F)$ & 0.000000 & 0.000000 & 0.000000 & 0.000000 & 0.000000 \\
\hline
\end{tabular}

* Significance $0.05, * *$ Significance 0.01

As the model reflects, the power-distance cultural dimension has the highest explanatory capacity. This factor even takes the place of the remaining cultural variables (model VII, Table 3, Graph 1). Consequently, a culture of dependency or, what is the same, the acceptance of social distances and culturally determined hierarchies is directly linked to high levels of corruption, above any other cultural dimension. 


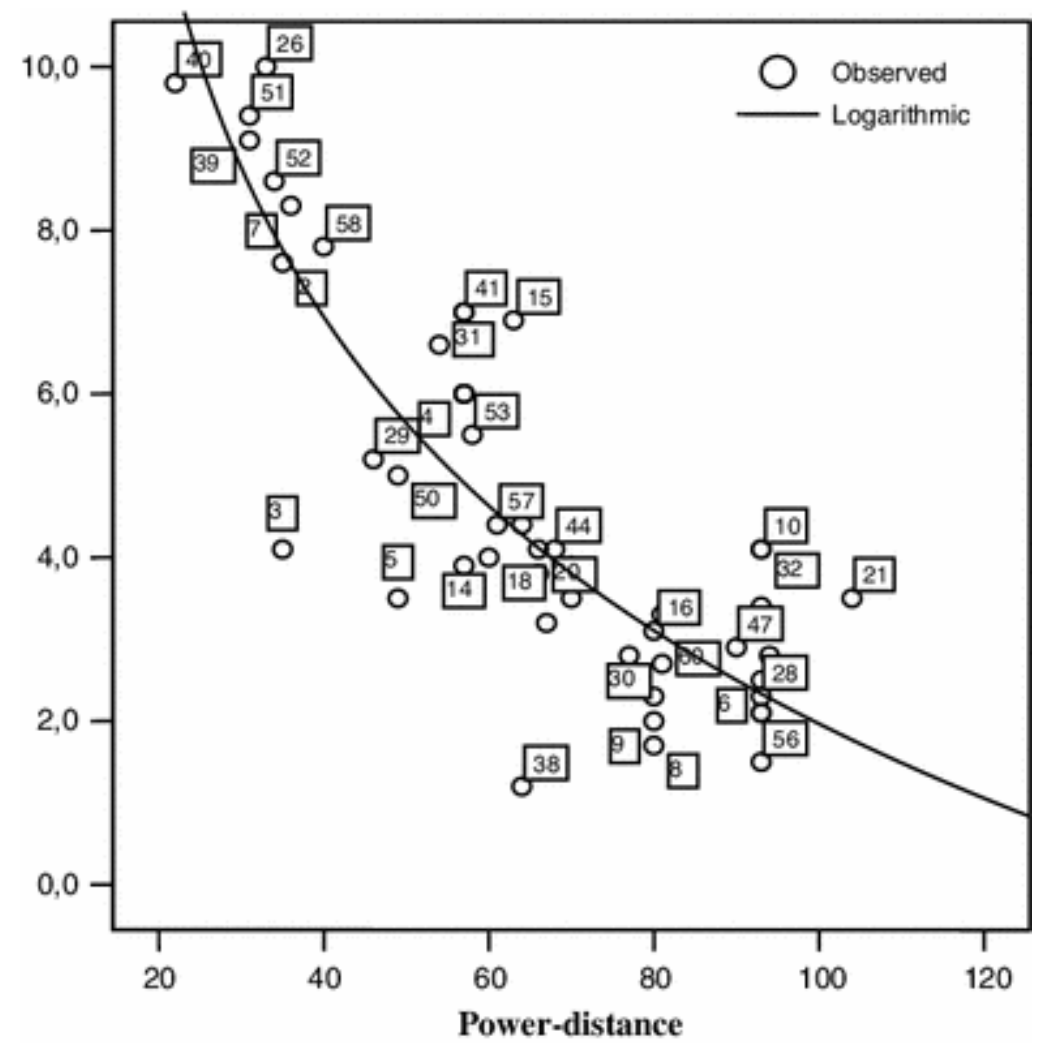

Graph 1

Corruption (transparency) versus power-distance. Source Authors' based on Hoffstede (1999) and K index (2001). 1 Albania, 2 West Germany, 3 East Germany, 4 Andalusia, 5 Argentina, 6 Armenia, 7 Australia, 8 Azerbaijan, 9 Bangladesh, 10 Belarus, 11 Bosnia, 12 Brazil, 13 Bulgaria, 14 Czech Republic, 15 Chile, 16 China, 17 Colombia, 18 South Korea, 19 Croatia, 20 El Salvador, 21 Slovakia, 22 Slovenia, 23 Spain, 24 Estonia, 25 Philippines, 26 Finland, 27 Galicia, 28 Georgia, 29 Hungary, 30 India, 31 Japan, 32 Latvia, 33 Lithuania, 34 Macedonia, 35 Mexico, 36 Moldova, 37 Morocco, 38 Nigeria, 39 Norway, 40 New Zealand, 41 Basque Country, 42 Pakistan, 43 Peru, 44 Poland, 45 Puerto Rico, 46 Dominican Republic, 47 Romania, 48 Russia, 49 Serbia, 50 South Africa, 51 Sweden, 52 Switzerland, 53 Taiwan, 54 Tambov, 55 Turkey, 56 Ukraine, 57 Uruguay, 58 USA, 59 Valencia, 60 Venezuela

As we said before, individualism measures the strength of the individual against the norms and values of human groups. Its opposite, collectivism, is characteristic of societies in which people are integrated into strong, cohesive groups from birth; groups which continue to protect them throughout life in exchange for loyalty. Between both dimensions there is a link, since a more individualistic culture presents a clear tendency to egalitarianism. However, two distinct evaluative dimensions are being dealt with.

As shown above (model III, Table 2), generalized trust as an indicator of positive social capital endowment in a country clearly relates inversely with the existence of corruption. To integrate the two variables (power-distance and trust) in the same 
model (model VIII, Table 3), allows higher levels of explicability, especially when particularistic trust indicators are incorporated (models IX and X, Table 3).

The estimation results confirm our proposals on the relations of the diverse expressions of social capital with corruption (Propositions 5 and 6) and two of the hypotheses about the impact of cultural dimensions on corruption. Specifically, the dimensions power-distance and individualism-collectivism have proved significant in the sense proposed (Propositions 1 and 2). The remaining two have not proved significant (Propositions 3 and 4).

In short, from the perspective adopted, corruption is explained primarily by a cultural substrate linked to the existing network of social relations, what we call a culture of dependency whereby the dependent subject considers the domination by a superior as legitimate. These attitudes favour the establishment of tacit non-contractual relationships between unequal subjects, where the inferior subject answers to the alleged benefits of the superior subject maintaining his/her loyalty. From the more strictly social scope, corruption has a clear inverse relationship with generalized trust or positive social capital. In contrast, the relationship between corruption and particularistic trust is direct.

Our results allow us to affirm that anticorruption policies should take into account the cultural context in order to foster their efficacy. Policies-based exclusively on principalagent analysis will not consider the cultural based contracts and networks that can account for a good part of the problem. Two measures seem to be important in order to avoid corruption: Education polices and monitoring forms of tacit contracts (amoral familism, stable political networks lack of transparency...).

\section{Conclusions}

The results of the analysis conducted in this paper highlight the role of structural social and cultural factors as determinants of corruption.

From the estimation of the models we derive that there is a clear inverse relationship between positive social capital endowments expressed through generalized trust and transparency (negative with corruption). We also evidenced the paradoxical nature of particularistic relations of mutual trust. Under these circumstances, if "moral sentiments" do not restrict exchanges in strictly legal terms, reciprocity becomes the collateral and substrate of corruption. Consequently, we have to distinguish between positive (generalistic) and negative (particularistic) expressions of social capital. The latter have an opposite effect.

Moreover, under a broader sociocultural perspective, empirical evidence suggests that corruption is clearly explained by a sociocultural substrate that we have denominated culture of dependency. This appears associated with particularistic forms of trust (negative social capital) and a culture that legitimates power relations and social distance. In this situation corruption found a favourable context in networks of reciprocity (amoral familism) where trust is linked more so to individual networks of 
dependency than towards society as a whole. Thus, some countries are more likely to have high levels of corruption or conditions conducive to reinforcing these activities.

Since corruption depends on cultural variables, public intervention capabilities are greatly reduced, at least in the short term. Our results would support action on the political variables of an economy in order to reduce corruption levels. By way of example, the expansion of freedoms and democratization, as well as the generation of cultures of trust and a proper institutional framework design, constitute some of the most effective ways to achieve this goal. Nevertheless, social capital endowments are the result of secular investment processes and have proved remarkably stable. Consequently, the possibilities of influencing these contexts in the short-term are limited. Nevertheless, other factors such as competition in the newspaper industry or even within political parties and educative policy can have positive effects.

In this same area of public policies, we must take into account cases where corruption is almost the rule. In these scenarios, the efficiency of anticorruption laws would be severely curtailed because they do not eliminate the cause. In addition, although such laws increase the risk of these exchanges, on the other hand, they reinforce stability and closure of corruption networks. In such contexts, the creation of mobility mechanisms could avoid generating stable relationships of dependency or trust between customers and agents, and limit the agents' power.

One limitation of our study is the macrosocial perspective. In this sense, future studies should take into account a microsocial one. From the behavioural point of view, it would be interesting to study the individual determinants of corruption on microdata.

\section{Footnotes}

1.

With respect to Economics, corruption has been integrated into the research agenda for the last quarter of XX century, as international data on this problem emerged and the institutionalist research program was developed. The seminal works of Rose-Ackerman $(1975,1978)$ are an essential reference as the booting of a purely economic approach to the problems of corruption. Zamagni (1999) reviewed the main studies on the subject.

2.

However, the existence of divergent explanatory guidelines should be noted. Some studies have shown that the relationship between corruption and output levels are not monotonic (Kaufmann and Kraay 2002; Canavese 2006). According to these approaches, under certain circumstances of inefficiency in the functioning of government, corruption may be a second best that mitigates the deficiencies of the bureaucracy. 
3.

In general, the appropriation by individuals of the instruments that the government has at its disposal reduces the state's ability to play its role on market correction. To a certain extent, this process could be interpreted as a privatization of the state but without returning the role played to the market, and instead to bureaucracy (LaPorta et al. 1998; Tanzi 1998; Leite and Weidmann 1999). Moreover, reducing the discretion of public officials and the decentralization of authority has been significant insomuch as reducing corruption in economies penetrated by market relations (Johnson et al. 1998; Fisman and Gati 2002; Treisman 2000; Kranton 1996). At the same time, competition within the press and even political competition are very effective in reducing corruption. Thus, corruption is a particularly salient problem in authoritarian regimes (Treisman 2000).

4.

NSE affirms that it is inappropriate to consider corruption as the exclusive result of inadequate organizational and institutional framework. This proposal adopts the basic results of the New Institutional Economics (NIE) and its derivatives on Game Theory (transaction costs, probability of uncovering...) as a starting point, but completes them with an analysis of the cultural roots of corruption.

5.

Previous studies have applied the Hofstede model for modelling market ethics (Vitell et al. 1993), although the economic variables are not specifically included in them, limiting the analysis to the perception of ethical problems and the existence of informal codes of behaviour.

6.

In this respect it is noted that the larger the group the greater coercion, since the defection of a single member poses a risk to the others. This is the case of the mafia.

7.

Trust is measured as the percentage of the population that recognizes having trust in society as a whole (generalistic) or in a particular institution (family, unions...).

8.

The only factor that is irrelevant or not significant is the masculine-feminine dimension. This is the only variable that is independent of any other cultural and social expression. In fact, Hofstede (1999) himself believes that it 
integrates aspects that can have different manifestations regardless of the levels of development of a society.

9.

Horizontal associations are groups formed spontaneously between peers, on the contrary, vertical associationism is related with top-down groups directly linked with some forms of authority (political parties...).

10.

We applied ordinary least squares linear models using cross section data.

11.

The Global Economic Freedom Index is a pool indicator composed of several related indices.

12.

In all models we find a combination of high $R^{2}$ values and high significance of regressors, so that problems derived from the existence of multicollinearity are limited.

\section{References}

1. Akçay, S. (2006). Corruption and human development. Cato Journal, 26, 29-48.

2. Becker, G. (1968). Crime and punishment: An economic approach. The Journal of Political Economy, 76, 169-217.

3. Becker, G., \& Landes, W. (1974). Essays in the economics of crime and punishment. National Bureau of Economic Research.

4. Bjornskov, C. (2004). Corruption and social capital, Working Paper 03-13, Aarhus School of Business, Department of Economics.

5. Bourdieu, P. (1986). The forms of capital. In J. G. Richardson (Ed.), Handbook of theory and research for the sociology of education. New York: Greenwood.

6. Canavese, A. J. (2006). Corrupción organizativa y asignación de recursos. Desarrollo Económico, 45, 473-485.

7. Coleman, J. (1988). Social capital and the creation of human capital. American Journal of Sociology, 94, 95-120.

8. Fisman, R., \& Gati, R. (2002). Decentralization and corruption: Evidence across countries. Public Choice, 83, 325-345.

9. Freisitzer, K. (1981). Gesellschaftliche Bedingungen der Korruption-Versuch einer verhaltenswissenschaftlichen Deutung. In Brünner, C. (Ed.), Korruption und Kontrolle (S.151-163). Wien.

10. Geertz, C. (1957). Ritual and social change. American Anthropologist, 59, 32-54.

11. Goode, R. (1984). Government finance in developing countries. Washington, DC: Brookings Institute.

12. Graeff, P. (2005). Why should one trust in corruption? The linkage between corruption, norms and social capital. In Lambsdorff, J., Taube, M., \& Schramm, M. (Eds.), The new institutional economics of corruption. London: Routledge. 
13. Griesshaber, N., \& Geys, B. (2011). Civic engagement and corruption in 20 European democracies: Separating the bright form the dark side. Discussion Paper, WZB, Berlin.

14. Grootaert, Ch. (1998). Social capital: The missing link? Social Capital Initiative, Working Paper no. 3, Washington, DC: World Bank

15. Hall, R., \& Jones, C. I. (1999). Why do some countries produce so much more output per worker than others? Quarterly Journal of Economics, 114, 83-116.

16. Hofstede, G. (1999). Culturas y organizaciones. El software mental. Madrid: Alianza Editorial.

17. Hofstede, G. (2003). Culture's consequences, comparing values, behaviors, institutions and organizations across nations (2nd ed.). Newbury Park: Sage.

18. Hunt, S., \& Vitell, S. (1986). A general theory of marketing ethics. Journal of Macromarketing, 8, 5-16.

19. Husted, B. W. (1994). Honour among thieves: A transaction-cost interpretation of corruption in third world countries. Business Ethics Quarterly, IV, 17-27.

20. Husted, B. W. (1999). Wealth, culture and corruption. Journal of International Business Studies, 30, 339-359.

21. Jain, A. K. (2001). The political economy of corruption (pp. 111-141). New York: Routledge Press.

22. Johnson, S., Kaufmann, D., \& Zoido-Lobaton, P. (1998). Regulatory discretion and the unofficial economy. American Economic Review, 88, 387-392.

23. Kaufmann, D., \& Kraay, A. (2002). Growth without gobernance. The World Bank Discussion Paper, Washington DC.

24. Kluckhohn, C. (1951). The study of culture. In: D. Lerner \& H. D. Lasswell (Eds.), The policy sciences. Stanford: Stanford University Press.

25. Kluckhohn, C., Parsons, T., \& Shils, E. (1951). Values and value-orientations in the theory of action, toward a general theory of action. Cambridge, MA: Harvard University Press. Kranton, R. E. (1996). Reciprocal exchange: A self-sustaining system. American Economic Review, 86, 830-851.

26. Lambsdorff, J. G. (1998). Corruption in comparative perception. In: A. Jain (Ed.) Economics of corruption. Boston: Kluwer

27. Lambsdorff, J. G. (2002). Corruption and rent-seeking. Public Choice, 113, 97-125.

28. Lambsdorff, J., Taube, M., \& Schramm, M. (2005). Corrupt contracting: Exploring the analytical capacity of new institutional economics and new economic sociology. In: Lambsdorff, J., Taube, M., \& Schramm, M. (Eds.), The new institutional economics of corruption. London: Routledge.

29. Laporta, R., Lopez-de-Silanes, F., Shleifer, A., \& Vishny, R. (1998). Law and finance. Journal of Political Economy, 106, 1113-1155.

30. Leite, C., \& Weidmann, J. (1999). Does mother nature corrupt? Natural resources, corruption and economic growth. IMF Working Paper 99/85.

31. Mauro, P. (1995). Corruption and growth. Quarterly Journal of Economics, 110, 681712.

32. Olson, M. (1965). The logic of collective action. Cambridge: Harvard University Press. Ouchi, W. G. (1981). Theory Z: How American business can meet the Japanese challenge. Addison-Wesley.

33. Paldam, M. (2002). The cross-country pattern of corruption: Economics, culture and the seesaw dynamics. European Journal of Political Economy, 18, 215-240.

34. Paldam, M., \& Svendsen, G. T. (2002). Missing social capital and the transition in Eastern Europe. Journal for Institutional Innovation, Development and Transition, 5, 21-34.

35. Parsons, T., \& Shils, E. (1990). Values and social systems. In: J. Alexander \& S. Seidman (Eds.), Culture and society, contemporary debates. Cambridge University Press: New York. 
36. Pena López, J. A., \& Sánchez Santos, J. M. (2009). La dotación de capital social como factor determinante de la corrupción. Revista de Economía Mundial, 22, 197-220.

37. Putnam, R. (1993). Making democracy work: Civic traditions in modern Italy. Princeton, NJ: Princeton University Press.

38. Riley, S. (1998). The political of anticorruption strategies in Africa. In M. Robinson (Ed.), Corruption and development. London: Frank Cass.

39. Rose-Ackerman, S. (1975). The economics of corruption. Journal of Public Economics, 4, 187-203.

40. Rose-Ackerman, S. (1978). Corruption. A study in political economy. New York: Academic Press.

41. Rose-Ackerman, S. (1999). Corruption and government. Causes, consequences, and reform. Cambridge: Cambridge University Press.

42. Rose-Ackerman, S. (2000). Is leaner government necessarily cleaner government? In: J. Tulchin \& R. Espach (Eds.), Combating corruption in Latin America (pp. 87-104). Washington DC: W. Wilson Center Press.

43. Schwartz, S. (1994). Are there universal aspects in the structure and content of human values? Journal of Social Issues, 50, 19-45.

44. Seleim, A., \& Bontis, N. (2009). The relationship between culture and corruption: A cross-national study. Journal of Intellectual Capital, 10, 165-184.

45. Sen, A. K. (1997). Economics, business principles and moral sentiments. Business Ethics Quarterly, 7, 5-15.

46. Shihata, I. (2000). The role of the World Bank in combating corruption In: J. Tulchin \& R. Espach (Eds.), Combating corruption in Latin America (pp. 205-209). Washington DC: W. Wilson Center Press.

47. Tanzi, V. (1994). Corruption, government activities, and markets. IMF Working Paper No. $94 / 99$.

48. Tanzi, V. (1998). Corruption around the world causes, consequences, scope, and cures. IMF Staff Papers. 45, 4.

49. Tönnies, F. (1947). Comunidad y sociedad. Losada: Buenos Aires.

50. Treisman, D. (2000). The causes of corruption: A cross-national study. Journal of Public Economics, 73, 399-457.

51. Uslaner, E. (2002). The moral foundations of trust. New York: Cambridge University Press.

52. Uslaner, E. (2005). Trust and corruption. In J. Lambsdorff, M. Taube, \& M. Schramm (Eds.), The new institutional economics of corruption. London: Routledge. Vitell, S., Nwachukwu, S., \& Barnes, J. (1993). The effects of culture on ethical decision-making: An application of Hofstede's typology. Journal of Business Ethics, 10, 753-760.

53. Weber, M. (1964). Economía y Sociedad. Méjico: FCE.

54. Woolcock, M. (2001). The place of social capital in understanding social and economic outcomes. Canadian Journal of Policy Research, 2, 1492-1525.

55. Zamagni, S. (1999). The economics of corruption and illegal markets. Cheltenham, E. Elgar, 3 Vols. 